\title{
Correction to: Pure Shearing and Pure Distortional Deformations Are Not Equivalent
}

\section{M.B. Rubin ${ }^{1}$}

Accepted: 29 March 2021 / Published online: 16 June 2021

(c) Springer Nature B.V. 2021

\section{Correction to: Journal of Elasticity (2020) 142: 383-393 \\ https://doi.org/10.1007/s10659-020-09798-1}

The second equation in Eqn. (8) should be replaced by

$$
\sigma_{2}^{\prime \prime}=\frac{2 \sigma_{e}}{3} \sin \beta
$$

Acknowledgement The author would like to thank K. Heiduschke for discovering this typographical error.

Publisher's Note Springer Nature remains neutral with regard to jurisdictional claims in published maps and institutional affiliations.

The original article can be found online at https://doi.org/10.1007/s10659-020-09798-1

$\triangle$ M.B. Rubin

mbrubin@tx.technion.ac.il

1 Faculty of Mechanical Engineering, Technion-Israel Institute of Technology, 32000 Haifa, Israel 